
И ИНЫХ ДОСУДЕБНЫХ ПРОЦЕДУР В ЗАРУБЕЖНЫХ ЮРИСДИКЦИЯХ

КНЯЗЕВ Дмитрий Владимирович, заведующий кафедрой гражданского процессуального права Западно-Сибирского филиала Российского государственного университета правосудия, кандидат юридических наук

634050, Россия, г. Томск, пл. Ленина, 2

E-mail: kdv1979@inbox.ru

Недавние изменения в арбитражном процессуальном законодательстве требуют обязательного принятия сторонами мер по досудебному урегулированию спора. Федеральным законом от 1 июля 2017 г. № 147-ФЗ уточнено, что этот порядок подлежит применению только в отношении гражданско-правовых споров о взыскании денежных средств по требованиям, возникшим из договоров, других сделок, вследствие неосновательного обогащения.

Вопрос о необходимости досудебного урегулирования правового спора в зарубежных юрисдикциях решается по-разному. Если такой порядок предусмотрен, то закон, как правило, предъявляет подробные требования к претензии: существо требований, правовое и фактическое обоснование; требования к ответу на претензию: он должен быть обоснованным, при необходимости содержать встречные обоснованные требования; от сторон уже на этом этапе требуется раскрыть аргументы и доказательства, на которые они ссылаются. Стороны стимулируются к внесудебному разрешению правовых конфликтов; даже при неудаче в примирении стороны обращаются в суд с более осознанным пониманием своих притязаний; обостряются действительно важные вопросы, требующие вмешательства суда; уменьшается нагрузка на судебную систему.

Автор утверждает, что в нынешнем виде норма ч. 5 ст. 4 АПК РФ не позволяет досудебной процедуре выполнять ее функции, неразрешенными остаются ключевые вопросы: о цели соблюдения сторонами досудебного порядка и его задачах; роли ответчика в досудебной процедуре; о том, каким видится ее позитивный результат; что будет, если стороны подошли к этой процедуре формально; что соблюдение процедуры дает судебному процессу в случае ее неудачи; о процессуальных последствиях поведения сторон при досудебном урегулировании. Предлагается ч. 5 ст. 4 АПК РФ дополнить сообразно выявленным недостаткам.

Ключевые слова: арбитражный процесс, досудебные процедуры, претензионный порядок, досудебное примирение.

\title{
PRE-TRIAL SETTLEMENT OF COMMERCIAL DISPUTES IN THE ARBITRAL PROCEEDING IN THE FIELD OF CONCILIATION AND OTHER PRE-TRIAL SETTLEMENT IN FOREIGN JURISDICTIONS
}

D. V. KNYAZEV, head of the Department of civil procedural law of the Western-Siberian branch of the Russian State University of Justice, candidate of legal sciences

2, Lenin sq., Tomsk, Russia, 634050

E-mail: kdv1979@inbox.ru

Recent amendments to commercial procedure legislation require parties to take pre-trial dispute settlement actions. In the Federal Law from the $1^{\text {st }}$ July 2017 the legislator specified that this procedure should be applied only to civil disputes on money collection for claims arising from contracts and other transactions due to unreasonable gains. The question of the need for the pre-trial settlement of a legal dispute in foreign jurisdictions is resolved in different ways. If such a procedure is introduced, then the law, as a rule, presents detailed claims to answer to the claim: the essence of the claims, the legal and factual justification; requirements to answer to the claim: it must be justified, if necessary, and contain counter-reasonable claims; the parties at this stage are already required to disclose the arguments and evidence to which they refer. The parties are encouraged to out-ofcourt settlement of legal conflicts; even in case of reconciliation failure, the parties recourse to the court with a more conscious understanding of their claims; really important issues that require court intervention "exacerbates"; it reduces the burden on the judicial system. 
The author claims that, in its current form, the provision of the Article 4 Part 5 of the Arbitration Procedure Code of the Russian Federation does not allow the pre-trial procedure to perform its functions, the key issues remain unresolved: the purpose of the parties' compliance with the pre-trial procedure and its tasks, the role of the defendant in the pre-trial procedure, how its positive result is seen, what will happen if the parties approached this procedure formally, what the outcome of the compliance with the procedure is for the court process in case of its failure, the procedural consequences of the behavior of the parties in the pre-trial settlement. It is proposed to supplement the current norm in accordance with the revealed shortcomings.

Keywords: arbitration procedure, pre-trial procedures, complaint procedure, pre-litigation conciliation.

DOI: 10.12737/article_5a1e71d7aa4f81.66482827

И зменения, внесенные в ч. 5 ст. 4 АПК РФ Федеральным законом от 2 марта 2016 г. № 47-Ф3, предусматривают обязательное принятие сторонами мер по досудебному урегулированию спора. Федеральным законом от 1 июля 2017 г. № 147-Ф3 «О внесении изменений в статьи 1252 и 1486 части четвертой Гражданского кодекса Российской Федерации и статьи 4 и 99 Арбитражного процессуального кодекса Российской Федерации» законодатель уточнил, что этот порядок подлежит применению только в отношении гражданско-правовых споров о взыскании денежных средств по требованиям, возникшим из договоров, других сделок, вследствие неосновательного обогащения.

Вопрос о необходимости досудебного урегулирования правовых споров в зарубежных юрисдикциях решается по-разному. В зависимости от обязательности (или необязательности) соблюдения, а также характера такого порядка для всех или только части гражданских дел возможно выделить четыре группы государств.

Первая группа. Законодательство большинства зарубежных стран не предусматривает требований относительно обязательного досудебного урегулирования правовых споров. Это утверждение будет верным, в частности, в отношении Австрии, Бразилии, Германии, Гонконга, Индии, Ирландии, Испании, Мексики, ОАЭ, Польши, Португалии, Республики Гана, Республики Кипр, Республики Коста-Рика, Республики Эквадор, Сингапура, США, Турции, Финляндии, Швеции, ЮАР, Южной Кореи ${ }^{1}$.

Вторая группа. Правовые системы некоторых государств оговаривают обязательное претензионное урегулирование спора по части гражданских дел. Гражданский процессуальный закон Китая предусматривает досудебный порядок урегулирования трудовых споров; по искам акционеров истцу прежде не-

${ }^{1}$ Cm.: Practical Law. Dispute Resolution Global Guide. Thomson Reuters. URL: https://uk.practicallaw.thomsonreuters. com/Browse/Home/International/DisputeResolutionGlobalGuide? transitionType=Default\&contextData=(sc.Default) (дата обращения: 28.07.2017) (далее указано как: Practical Law... и соответствующая страна); International Comparative Legal Guides. Litigation \& Dispute Resolution 2017. Reuters. URL: https://iclg. $\mathrm{com} /$ practice-areas/litigation-and-dispute-resolution/litigationand-dispute-resolution-2017\#jurisdictions (дата обращения: 28.07.2017) (далее указано как: International Comparative Legal Guides... и соответствующая страна). обходимо получить согласие коллегиального исполнительного органа ${ }^{2}$.

В Дании по делам о взыскании долга истец обязан направить письмо с требованием об оплате долга и предоставить должнику не менее 10 дней на полное исполнение обязательства ${ }^{3}$.

В Чешской Республике, если истец желает, чтобы обязательство было принудительно исполнено с помощью суда, он должен предварительно направить должнику уведомление о необходимости исполнения обязательства в указанный в уведомлении срок. Неисполнение этого требования истцом влечет для него утрату права на компенсацию судебных расходов в случае выигрыша дела ${ }^{4}$.

В Японии законодательство по общему правилу не требует соблюдения каких-либо досудебных процедур. Исключения предусмотрены для дел об оспаривании некоторых решений государственных органов. Кроме того, по делам об оспаривании размера арендной платы за пользование недвижимым имуществом истец обязан использовать медиативные процедуры перед обращением в суд 5 .

В третьей группе состоят страны, в которых требуется обязательное использование специфических примирительных процедур до обращения в суд. В частности, в Буэнос-Айресе и некоторых других провинциях Аргентины перед обращением в суд стороны должны инициировать обязательную досудебную медиативную процедуру. Если стороны не достигли соглашения в ходе медиации, медиатор готовит специальный документ, свидетельствующий о том, что медиация окончена. После этого сторона получает право на обращение в суд 6 .

В Румылиии начиная с 1 августа 2013 г. по некоторым категориям дел (о защите прав потребителей, семейным, трудовым, при цене иска до 50000 румынских лей) требуется участие сторон в медиации до обращения в суд. Однако решением Конституционно-

${ }^{2}$ Cм.: Practical Law... Litigation and Enforcement in China: Overview.

${ }^{3}$ См.: Practical Law... Litigation and Enforcement in Denmark: Overview.

${ }^{4}$ См.: International Comparative Legal Guides... Czech Republic.

${ }^{5}$ CM.: International Comparative Legal Guides... Japan.

${ }^{6}$ CM.: Practical Law... Litigation and Enforcement in Argentina: Overview. 
го суда Румынии № 266/2014 данная норма признана неконституционной ${ }^{7}$.

В Лихтенштейне за исключением некоторых видов судопроизводства перед обращением в суд требуется участие в медиативных процедурах.

На Филиппинах предусмотрено, что лица, проживающие в одном городе или муниципалитете, между которыми возник спор, должны пройти процедуру примирения перед советом муниципалитета (lupong tagapamayapa) ${ }^{8}$. Несоблюдение этого требования влечет отклонение иска9.

Гражданский процессуальный кодекс Швейцарии (ст. 197 ГПК, процедуре примирения посвящен целый раздел ГПК) предусматривает обязанность сторон предпринять попытку примирения перед обращением в суд. Для этого существует особый примирительный орган. Оговариваются и исключения - дела, по которым примирение не проводится: в рамках упрощенного производства, по делам о гражданском статусе лица, о разводе и проч. ${ }^{10}$

Наконец, четвертая группа объединяет государства, законодательство которых устанавливает соблюдение сторонами досудебного (претензионного) порядка урегулирования споров в качестве необходимого условия для обращения в суд. Так, согласно п. 1 приложения 1 к Хозяйственному процессуальному кодексу Республики Беларусь ${ }^{11}$ лицо, чьи права или законные интересы нарушены, с целью непосредственного урегулирования спора с нарушителем этих прав или интересов обязано предъявить ему претензию (письменное предложение о добровольном урегулировании спора), если иное не установлено законодательными актами или договором. Предусматриваются подробные требования к претензии (п. 2). При рассмотрении претензии стороны при необходимости сверяют расчеты, проводят экспертизу или совершают другие действия для обеспечения досудебного урегулирования спора (п. 5). Предусматривается ме-

${ }^{7}$ См.: International Comparative Legal Guides... Lithuania; The Dispute Resolution Review. $7^{\text {th }}$ ed. URL: https://www.amcham. ro/UserFiles/articleFiles/The\%20Dispute\%20Resolution\%20 Review\%202015_Romania_03261319.pdf (дата обращения: 28.07.2017).

${ }^{8}$ Section 408, Republic Act 7160. URL: http://www.lawphil. net/statutes/repacts/ra1991/ra_7160_1991.html (дата обращения: 28.07.2017).

${ }^{9}$ Section 1, Rule 16, Rules of Court. URL: http://www. chanrobles.com/rtcprocedure.htm\#RULE\%2016 (дата обращения: 28.07.2017); Practical Law... Litigation and Enforcement in the Philippines: Overview.

${ }^{10}$ Swiss Civil Procedure Code (Civil Procedure Code, CPC) of 19December2008(Statusas of 1 May2013).URL:https://www.admin. ch/opc/en/classified-compilation/20061121/201601010000/272.pdf (дата обращения: 28.07.2017).

${ }^{11}$ URL: http://kodeksy.by/hpk/prilozhenie-1 (дата обращения: 28.07.2017). сячный срок для ответа на претензию (п. 6). Интересной деталью является то, что неполучение ответа на претензию в установленный п. 6 настоящего приложения срок не препятствует предъявлению претензии в качестве доказательства признания (неоспаривания) получателем претензии требований, заявленных в порядке приказного производства (п. 8).

В соответствии со ст. 6 Хозяйственного процессуального кодекса Украины предприятия и организации, чьи права и законные интересы нарушены, в целях непосредственного урегулирования спора с нарушителем этих прав и интересов обращаются к нему с письменной претензией. Предусматриваются требования к содержанию претензии. На рассмотрение претензии по общему правилу отводится один месяц ${ }^{12}$.

С 1 апреля 2015 г. во Франции действует декрет от 11 марта 2015 г. № 2015-282, которым внесены изменения в ст. 56 Гражданского процессуального кодекса: «За исключением случаев, не терпящих отлагательства, или в связи со спецификой спорных вопросов, особенно когда это касается национальных интересов, в исковом заявлении также должны быть указаны шаги, которые были предприняты в целях мирного урегулирования спора». Иными словами, за исключением особых дел (которые в большей степени касаются срочности или вопросов государственной политики) стороны должны предпринять попытки мирно разрешить свой спор перед обращением в суд, о чем должно быть указано в исковом заявлении ${ }^{13}$. Однако особенность приведенного порядка состоит в том, что закон не связывает с несоблюдением указанного требования применение санкций. Невыполнение этой обязанности не означает порок искового заявления. Единственное последствие состоит в том, что судья может «предложить сторонам провести примирительную процедуру» (ст. 127 ГПК Франции) $)^{14}$.

Соединенное Королевство Великобритании и Северной Ирландии. Досудебные процедуры, предусмотренные законодательством этой страны, вызывают наибольший интерес, так как являются максимально разработанными. В 1995-1996 гг. вышли доклады ${ }^{15}$ лорда Вулфа относительно реформирования

12 Досудебному урегулированию хозяйственных споров посвящен разд. II Кодекса. URL: http://kodeksy.com.ua/ka/ hozajstvennyj_protsesual_kodeks_ukrainy.htm (дата обращения: 28.07.2017).

${ }^{13}$ URL: http://www.august-debouzy.com/en/blog/894-newmandatory-provisions-contained-in-articles-56-and-58-ofthe-french-code-of-civil-procedure-what-changes-have-beenimplemented (дата обращения: 09.03.2017).

${ }^{14}$ URL: http://www.lexology.com/library/detail.aspx?g= f5730aa0-ed56-47b1-874b-de60d71c5547 (дата обращения: 09.03.2017).

${ }^{15}$ Access to Justice, Interim Report, (Lord Chancellor's Department, June 1995); Access to Justice, Final Report. L.: HMSO, 1996. 
гражданского судопроизводства Соединенного Королевства, которые впоследствии легли в основу Правил гражданского судопроизводства 1998 г. (далееПГС) ${ }^{16}$. Тогда же вступили в силу практические указания «Досудебное поведение сторон и протоколы» ${ }^{17}$. На момент введения в дейсвие протоколов специальный досудебный порядок устанавливался лишь для двух категорий дел, сейчас — для $13^{18}$.

При этом прямо закреплено правило о том, что судебное разбирательство должно быть крайней мерой. Стороны должны выявить возможность окончания спора с помощью переговоров или иных внесудебных процедур без инициирования судебного процесса (§ 8). Если спор до суда не разрешен, то сторонам следует, как минимум, выяснить предмет спора перед обращением истца в суд (§ 12). Если судебный процесс все же начат, суд может потребовать представления доказательств того, что стороны обсуждали использование альтернативных процедур. Молчание стороны в ответ на предложение поучаствовать в такой процедуре, а также отказ от такового могут быть расценены судом как неразумные и могут привести к наложению на сторону дополнительных судебных расходов (§ 11).

Досудебные протоколы устанавливают поведение сторон и шаги, которые должны быть ими предприняты перед возбуждением гражданского дела в суде. Декларируется цель как самих досудебных протоколов, так и всего процесса кейс-менеджмента - содействовать и побуждать к заключению соглашения на самых ранних стадиях ${ }^{19}$. Профессор Н. Эндрюс (N. Andrews) поясняет: основная цель английской системы досудебных протоколов состоит в том, чтобы содействовать раннему урегулированию споров и избежать расходов и неудобств, которые вызывает судебное разбирательство. Корни такого воззрения лежат в представлении о судебном процессе, особенно о разбирательстве дела по существу, как о форме разрешения спора, которая должна рассматривать-

${ }^{16}$ The Civil Procedure Rules, 1998.

${ }^{17}$ Practice Direction - Pre-Action Conduct and Protocols. Отметим, что до введения указанных протоколов какого-либо акта, регулировавшего отношения между сторонами до процесса, в Англии не существовало (см.: Кудрявцева Е. В. Гражданское судопроизводство Англии. М., 2008. С. 31).

18 Это дела о причинении вреда, разрешении врачебных споров, строительном подряде и проектировании, диффамации, профессиональной халатности, об оспаривании актов органов исполнительной власти, о заболеваниях и болезни, содержании домовладений, владении по социальному найму; по искам о владении по ипотечной задолженности, разрушении коммерческой недвижимости, по искам на невысокую сумму о взыскании ущерба в связи с ДТП и причинением вреда на рабочем месте и др.

${ }^{19}$ Cм.: Jolowicz J. A. On Civil Procedure. Cambridge University Press, 2000. P. 392. ся в качестве «крайнего средства»... Каждая сторона должна знать сильные аспекты позиции противоположной стороны. Кроме того, выражается надежда, что эффективный обмен информацией будет способствовать заключению сторонами соглашения ${ }^{20}$. Так, сформулированы следующие цели досудебного поведения и протоколов: до инициирования судебного разбирательства суд будет ожидать от сторон обмена достаточной информацией для того, чтобы понять позиции друг друга, принять решения относительно того, как действовать дальше, попытаться урегулировать спор без судебного разбирательства, обсудить форму альтернативного разрешения спора для достижения соглашения, уменьшить стоимость разрешения спора (§ 3 Практического указания).

Стороны должны предпринимать только разумные шаги для установления, уточнения и разрешения спорных положений иска. Расходы сторон в ходе выполнения протоколов должны быть пропорциональны. Протоколы по отдельным категориям дел это подробные инструкции относительно того, какие действия должны быть предприняты сторонами до обращения в суд. В остальных случаях (когда специальный протокол не предусмотрен) действует общее правило (§ 6), согласно которому стороны должны совершить ряд досудебных действий: истец направляет ответчику письменное обращение, в котором inter alia подробно излагает детали жалобы (основание иска, обзор фактов, требование истца к ответчику, если требование денежное, то расчет суммы иска) (§ 6 (а)). Ответчик обязан ответить в течение 14 дней по простым делам и трех месяцев по очень сложным делам. Ответ должен содержать информацию о признании или непризнании ответчиком требования. Если требование не признается, то должны быть указаны причины вместе с объяснением, какие факты и части требования оспариваются, планирует ли ответчик заявить встречное требование, его детали (§ 6 (b)). Кроме того, от сторон требуется раскрыть ключевые документы, подтверждающие притязания сторон (§ 6(c)).

Последствия выполнения сторонами предписания Практического указания закреплены в п. 13-16. Суд выясняет, насколько сторонами были исполнены требования специальных протоколов или Практического указания. При оценке поведения сторон принимается во внимания степень срочности вопроса. Предусмотрены основания для признания поведения сторон не соответствующим протоколам, суд может приостановить производство до выполнения сторонами требований протокола, а также применить санкции.

Несколько слов относительно того, какую оценку получают досудебные протоколы в английском

${ }^{20}$ См.: Andrews N. The Three Paths of Justice: Court Proceedings, Arbitration, and Mediation in England // Ius Gentium: Comparative Perspectives on Law and Justice. 2012. Vol. 10. P. 9. 
юридическом сообществе. Член Апелляционного суда Англии и Уэльса Р. Джексон (R. Jackson), в частности, указывает, что специальные протоколы практически единогласно одобряются юридическим сообществом, в то время как общий протокол (действующий при отсутствии специального) скорее не выполняет своей функции. По крупным коммерческим делам общий протокол способен вызвать значительные временные задержки и излишние расходы сторон ${ }^{21}$. Н. Эндрюс затрудняется дать однозначную оценку преимуществам системы протоколов, но вместе с тем отмечает, что необходимо соотносить возможность альтернативного урегулирования споpa, раскрытия информации и доказательств и очевидное в данном случае увеличение судебных расходов $^{22}$. Д. Дуаер (D. Dwyer) указывает, что в целом использование досудебных протоколов - это успех, однако замечает, что активность сторон на досудебной стадии вызывает дополнительные расходы сторон спора. При том, что этих расходов можно было бы избежать по делам, которые и так оканчиваются миром без какой-либо значимой предварительной работы сторон ${ }^{23}$.

На федеральном уровне Австралии принят Акт о разрешении гражданских споров $2011 \Gamma^{24}$, согласно которому истец при обращении в суд подает документ о том, что им предприняты «искренние», «истинные» меры (genuine steps) до обращения в суд. В этом документе должны быть указаны шаги, сделанные истцом для разрешения противоречий с ответчиком. Если подобных действий не было совершено, стороны должны объяснить причины. К уважительным причинам закон относит срочность, а также возможность появления опасности для лица или имущества. В последнем случае требуется охарактеризовать степень опасности.

В Норвегии истец не имеет права подать иск в суд или в примирительный совет ${ }^{25}$ без того, чтобы прежде письменно не уведомить об этом противоположную сторону. При этом обе стороны обязаны попытаться

${ }^{21}$ CM.: Jackson R. Review of Civil Litigation Costs: Final Report. The Stationery Office, 2009. P. 345. URL: https://www. judiciary.gov.uk/wp-content/uploads/JCO/Documents/Reports/ jackson-final-report-140110.pdf (дата обращения: 28.07.2017).

${ }^{22}$ См.: Эндрюс Н. Система гражданского процесса Англии: судебное разбирательство, медиация и арбитраж. М., 2012. C. 124.

${ }^{23}$ См.: The Civil Procedure Rules Ten Years On/ ed. by D. Dwyer N. Y., 2009. P. 13.

${ }^{24}$ Civil Dispute Resolution Act 2011 (No. 17, 2011). URL: http:// www.austlii.edu.au/au/legis/cth/num_act/cdra2011296/ (дата обращения: 28.07.2017).

${ }^{25}$ Conciliation Board. Традиционные органы по разрешению споров в Норвегии образовываются при муниципалитетах (см.: Backer I. L. (2007) The Norwegian Reform of Civil Procedure // Scand. Stud. Law. 51. P. 56). заключить мировое соглашение ${ }^{26}$. Так, норвежский Акт о спорах ${ }^{27}$ обязывает сторону, за исключением дел, касающихся административных решений, обратиться к предполагаемому ответчику письменно. Такое обращение должно содержать информацию о существе требования и его основаниях, а также приглашение оппонента ответить на требование и основания для него (s. 5-2 (1)). Лицо, получившее такое обращение, обязано ответить на него в разумный срок. Если требование оспаривается, то предполагаемый ответчик обязан пояснить, по каким основаниям он возражает. Если у ответчика имеются встречные требования, то они также должны быть заявлены, а первоначальный истец обязан отреагировать на них в том же порядке (s. 5-2 (2)). Сторона, направляющая требование или встречное требование, должна сообщить информацию о важных документах или иных доказательствах, о которых ей известно, и о которых, как она полагает, не известно сопернику. Причем правило применяется независимо от того, чью позицию усиливает доказательство (s. 5-3 (1)). В целом, действует правило, согласно которому стороны должны искать возможность заключения мирового соглашения до обращения в суд (s. 5-4).

Чтобы картина была более полной, стоит назвать страны, в которых истец и ответчик обязаны принять участие в примирительных процедурах сразу после обращения в суд (речь не идет о досудебном поведении сторон). Так, процессуальные правила канадских провинций зачастую предусматривают обязательное проведение медиативных процедур сразу после обращения истца с иском. К примеру, в Британской Колумбии и Онтарио все поступающие в суд дела направляются на медиацию, в других провинциях это делается выборочно ${ }^{28}$. Обязательная попытка медиативного урегулирования гражданского спора предусмотрена в Италии: суд не может приступить к рассмотрению дела по существу, пока стороны не предприняли попытку медиации ${ }^{29}$. В США в большинстве окружных судов и в судах штатов на стадии подготовки дела судья sua sponte направляет стороны на участие в какой-либо примирительной процедуре, в ряде случаев участие в таких процедурах обязательно по всем делам.

Обобщая сказанное, можно утверждать, что законодательство большинства государств не предусма-

${ }^{26}$ Ibid. P. $55-56$.

${ }^{27}$ Act of 17 June 2005 no. 90 Relating to Mediation and Procedure in Civil Disputes (The Dispute Act). URL: http://app.uio.no/ ub/ujur/oversatte-lover/data/lov-20050617-090-eng.pdf (дата обращения: 01.08.2017).

${ }^{28}$ Об обязательной медиации в Канаде см.: Князев Д. B. Принудительная (обязательная) медиация в гражданском процессе Канады // Третейский суд. 2014. № 5.

${ }^{29}$ См.: Гайдаенко Шер Н. И. Италия: возвращение обязательной медиации // Третейский суд. 2014. № 5. С. 189-190. 
тривает досудебного порядка урегулирования спора в качестве sine qua non при обращении в суд. Либо таких требований нет, либо они имеются лишь в отношении специально определенной группы споров, что обусловлено материальными особенностями самих споров. Страны, в которых законодательство требует от сторон соблюдения какого-либо досудебного порядка, немногочисленны, а если он установлен, то сформулирована цель, которую ставит законодатель перед сторонами конфликта. Так, в группе стран, в которых имеется требование об обязательном участии в специфических примирительных процедурах (третья группа), воля законодателя направлена на то, чтобы примирить стороны до передачи ими спора в суд. Закон государств, в которых предусмотрен досудебный претензионный порядок, как правило, содержит подробные предписания относительно содержания такой претензии (существо требований, правовое и фактическое обоснование); требования относительно ответа на претензию (должен быть обоснованным, при необходимости содержать встречные обоснованные требования). Наконец, от сторон уже на этом этапе требуется раскрытие аргументов и доказательства, на которые они ссылаются. Становится понятно, что стороны, во-первых, стимулируются к «бескровному», внесудебному разрешению правовых конфликтов, что, как признается многими, per se является безусловным общественным благом. Во-вторых, даже при недостижении соглашения в ходе примирения участники конфликта обращаются в суд с более осознанным пониманием своих притязаний друг к другу, «уходят» не оспариваемые обеими сторонами элементы иска (встречного иска), «обостряются» действительно важные вопросы, требующие вмешательства арбитра. В-третьих, на стороны налагается обязанность по раскрытию относящихся к делу информации и доказательств еще до обращения в суд. В-четвертых, в результате происходит уменьшение нагрузки на судебную систему. Как отмечается применительно к Великобритании, досудебные протоколы меняют саму сущность того, как начинается и проводится судебное разбирательство, в сторону подлинного обсуждения альтернативных способов разрешения спора. Протоколы «заставляют» спорящие стороны выявлять ключевые моменты своих требований и возражений до общения в суд ${ }^{30}$.

Вернемся в Россию. В пояснительной записке к проекту Федерального закона от 2 марта 2016 г. № 47-Ф3¹ говорится о том, что он направлен на реализацию задачи по оптимизации судебной нагрузки, изменения

${ }^{30}$ Cм.: Gerber P., Mailman B. (2005) Construction Litigation: Can We Do It Better? // Monash University Law Review. 31. P. 238.

${ }^{31}$ Опубликована на сайте Государственной Думы РФ. URL: http://asozd2.duma.gov.ru/main.nsf/(ViewDoc)?OpenAgent\& arhiv/a_dz_6.nsf/ByID\&CACD38B5DEEBD2EC 4325 7D8200394628 (дата обращения: 01.08.2017). направлены на развитие альтернативных способов разрешения споров, использование которых позволит повысить эффективность правосудия в целом, в том числе посредством уменьшения количества споров, которые могут стать предметом рассмотрения арбитражных судов; претензионный порядок или иной досудебный порядок, имеющий своей целью урегулирование спора, является действенным средством повышения качества работы судебной системы, способствует укреплению экономических связей, содействует становлению и развитию партнерских деловых отношений, способствует формированию обычаев и этики делового оборота и снижению конфликтности в обществе в целом ${ }^{32}$.

Заявленные цели и задачи заслуживают безоговорочной поддержки. Вместе с тем текст самого Закона явно не направлен на их реализацию. В нынешней редакции ч. 5 ст. 4 АПК РФ выглядит для сторон лишь как помеха, формальное препятствие на пути обращения в суд. Ни из указанного правила, ни из каких-либо других норм не ясно, с какой целью стороны должны соблюдать досудебный порядок, de lege lata этой цели нет. Какие задачи должны быть решены сторонами при соблюдении претензионного порядка? Задачи не сформулированы. Какова роль ответчика в досудебной процедуре? Сейчас смысл нормы таков, что реакция ответчика на претензию вовсе необязательна. Каким видится позитивный результат этой процедуры? Закреплен только негативный в виде возвращения искового заявления или оставления его без рассмотрения. Что будет, если стороны подошли к этой процедуре формально, «для галочки»? Нынешняя норма и не требует от сторон даже минимального «усердия» на пути примирения. Что соблюдение процедуры дает судебному процессу в случае ее неудачи: уточнение спорных вопросов факта или права, раскрытие относимых доказательств? Ничего из перечисленного. Каковы позитивные или негативные процессуальные последствия поведения сторон на стадии досудебного урегулирования, например, освобождение от судебных расходов с переложением их на противника? Никаких.

Указанные вопросы de lege ferenda должны разрешаться. Если законодатель пошел по пути введения обязательного досудебного порядка, то стороны по крайней мере должны понимать, для чего он нужен, что от них требуется и каковы последствия их поведения на досудебной стадии. Поэтому действующую

\footnotetext{
32 Отметим, что в пояснительной записке к Федеральному закону от 1 июля 2017 г. № 147-ФЗ какая-либо мотивировка относительно изменений ч. 5 ст. 4 АПК РФ и установления досудебного порядка разрешения споров лишь в отношении требований о взыскании денежных средств отсутствует. URL: http:/ asozd2.duma.gov.ru/main.nsf/(ViewDoc)?OpenAgent\&work/ dz.nsf/ByID\&F18863C4C988A21043258074004B484C (дата обращения: 01.08.2017).
} 
норму предлагается дополнить. В частности, должна быть сформулирована цель досудебной процедуры это мирное урегулирование, окончание спора между предполагаемыми истцом и ответчиком.

Перед сторонами должны быть поставлены задачи: стремиться к урегулированию всех или части спорных вопросов; предпринять максимальные усилия, чтобы сделать понятным для противоположной стороны существо требований и возражений, основания таких требований и возражений, выявить доказательства, на которых основываются требования или возражения сторон. Должен быть алгоритм действий сторон. Истец обязан письменно обратиться к ответчику с подробным изложением своего требования, в частности, в претензии должна содержаться информация о существе требований, об их фактическом и правовом основании; о расчете суммы требований; ключевых доказательствах, на которых основаны требова- ния; а также предложение удовлетворить требование истца. Ответчику следует ответить в установленный законом или договором срок. Ответ должен содержать следующие сведения: признает ли ответчик требование (полностью или в части); если требование ответчиком не признается, то какие факты и (или) части требования оспариваются; имеет ли ответчик встречные требования к истцу и планируется ли заявить их, в чем существо этих требований, каковы их основания; о ключевых доказательствах, на которых основаны возражения (требования) ответчика.

Предлагаемые изменения, думается, позволят придать существующей норме ч. 5 ст. 4 АПК РФ законченный вид, будут реализованы те устремления, которыми руководствовался законодатель при ее введении, а досудебный порядок позволит хотя бы отчасти реализовать мечту российских судей об уменьшении нагрузки.

\section{БИБЛИОГРАФИЧЕСКИЙ СПИСОК}

Andrews N. The Three Paths of Justice: Court Proceedings, Arbitration, and Mediation in England // lus Gentium: Comparative Perspectives on Law and Justice. 2012. Vol. 10.

Backer I. L. (2007) The Norwegian Reform of Civil Procedure // Scand. Stud. Law. 51.

Gerber P., Mailman B. (2005) Construction Litigation: Can We Do It Better? // Monash University Law Review. 31.

Jackson R. Review of Civil Litigation Costs: Final Report. The Stationery Office, 2009. URL: https://www.judiciary.gov.uk/wp-content/ uploads/JCO/Documents/Reports/jackson-final-report-140110.pdf.

Jolowicz J. A. On Civil Procedure. Cambridge University Press, 2000.

The Civil Procedure Rules Ten Years On / ed. by D. Dwyer. N. Y., 2009.

Гайдаенко Шер Н. И. Италия: возвращение обязательной медиации // Третейский суд. 2014. № 5.

Князев Д. В. Принудительная (обязательная) медиация в гражданском процессе Канады // Третейский суд. 2014 . № 5.

Кудрявцева Е. В. Гражданское судопроизводство Англии. М., 2008.

Эндрюс Н. Система гражданского процесса Англии: судебное разбирательство, медиация и арбитраж. М., 2012. 